\title{
Is there a context-dependent advantage of extra-pair mating in Tree Swallows?
}

\author{
Amos Belmaker, ${ }^{1 \mathrm{a} *}$ Kelly K. Hallinger, ${ }^{1 \mathrm{~b}}$ Rebecca A. Glynn, ${ }^{2}$ Mark F. Haussmann, ${ }^{2}$ and David W. Winkler ${ }^{1}$ \\ ${ }^{1}$ Department of Ecology and Evolutionary Biology, Cornell University, Ithaca, New York, USA \\ 2 Department of Biology, Bucknell University, Lewisburg, Pennsylvania, USA \\ ${ }^{a}$ Current address: The Steinhardt Museum of Natural History, Tel-Aviv University, Israel \\ ${ }^{\text {b }}$ Current address: Department of Ecology and Evolutionary Biology, University of Arizona, Tucson, Arizona, USA \\ * Corresponding author: belmakera@tauex.tau.ac.il
}

Submitted January 5, 2018; Accepted June 7, 2018; Published August 15, 2018

\begin{abstract}
The "good-genes" hypothesis to explain female extra-pair mating states that females benefit from this behavior by acquiring better genes for their offspring. Despite extensive research, results are mixed, and the predictions of the good-genes hypothesis have been met in fewer than half of published papers. One possible explanation for this lack of consensus is that the benefits of extra-pair copulation are context-dependent. Here we use chick size, the probability of fledging, and telomeres, the protective caps of chromosomes, as markers for individual quality. Telomere length (TelL) integrates across many stressors and covaries with probability of survival and reproductive success. To test whether benefits to extra-pair (EP) matings are context-dependent we look at the telomere length of extra-pair and within-pair offspring (EPO and WPO, respectively) reared either in experimentally enlarged broods or in broods left at their natural size. We predicted that EPO would have longer telomeres than WPO, and that this difference would be more pronounced among nutritionally limited nestlings reared in enlarged broods. Contrary to our predictions, EP status did not predict chick size or TelL of nestlings reared in either treatment group. EPO from enlarged broods had a higher probability of fledging than similarly reared WPO, but this effect was only seen after a separate analysis per group and not in the full model. Even though these results give mixed support to the good-genes hypothesis they also highlight the difficulty in choosing the proper metric and context.
\end{abstract}

Keywords: context-dependence, extra-pair mating, Tachycineta, telomere length, Tree Swallow

\section{¿Existe una ventaja contexto-dependiente del apareamiento extra-pareja en Tachycineta bicolor? \\ RESUMEN}

La hipótesis de los "genes buenos" que explica el apareamiento extra-pareja de la hembra establece que las hembras se benefician de este comportamiento mediante la adquisición de mejores genes para su descendencia. A pesar de una extensa investigación, los resultados son mixtos, y las predicciones de la hipótesis de los buenos genes han sido alcanzadas en menos de la mitad de los artículos publicados. Una explicación posible de esta falta de consenso es que los beneficios de la copulación extra-pareja (CEP) son contexto-dependientes. Aquí usamos el tamaño del polluelo, la probabilidad de emplumar y los telómeros, las capas de protección de los cromosomas, como marcadores de la calidad individual. La longitud del telómero (LTel) se integra a través de muchos estresores y co-varía con la probabilidad de supervivencia y el éxito reproductivo. Para evaluar si los beneficios de la CEP son contexto-dependientes, observamos la LTel de la descendencia extra-pareja e intra-pareja (DEP y DIP, respectivamente) criada ya sea en nidadas experimentalmente ampliadas o en nidadas con el tamaño natural. Predijimos que la DEP debería tener telómeros más largos que la DIP, y que esta diferencia debería ser más pronunciada entre polluelos con limitaciones nutricionales criados en nidadas ampliadas. Contrariamente a nuestras predicciones, el estatus EP no predijo el tamaño del polluelo o la LTel de los polluelos criados en cada grupo de tratamiento. La DEP proveniente de las nidadas ampliadas tuvo una mayor probabilidad de emplumar que la DIP criada de modo similar, pero este efecto fue solo percibido luego de un análisis separado por grupo y no en el modelo completo. Aunque estos resultados le otorgan un apoyo mixto a la hipótesis de los genes buenos, también resaltan la dificultad en elegir la métrica y el contexto apropiados.

Palabras clave: apareamiento extra-pareja, contexto-dependencia, longitud del telómero, Tachycineta bicolor

\section{INTRODUCTION}

Before the advent of the molecular revolution most passerine species were considered both socially and genetically monogamous (Lack 1968). However, after it became possible to easily and cheaply genotype many individuals in the wild (Jeffreys et al. 1985), it became clear that extra-pair (EP) mating is common (Griffith et al. 
2002). Attempts to explain why females may choose to mate with more than one male have yielded myriad hypotheses (reviewed in Griffith et al. 2002, Akçay and Roughgarden 2007). Though it has been suggested that female EP behavior is not adaptive (Forstmeier et al. 2014), there are many examples where a benefit to females has been found (Akçay and Roughgarden 2007). In addition, the fact that EP mating can be costly to females (Ferretti and Winkler 2009) suggests that there is some benefit that keeps this behavior from disappearing. In those cases where we cannot observe a benefit to females of EP mating, it is worthwhile to ask if the behavior is really not adaptive or if we just lack the ability to detect its benefit.

Females have been hypothesized to engage in EP behavior to guard against infertility in their social mate (Wetton and Parkin 1991, Sheldon 1994), to increase the genetic diversity of their brood (Williams 1975, Westneat et al. 1990), or to gain direct support in rearing their offspring (Wolf 1975, Burke et al. 1989, Colwell and Oring 1989, Townsend et al. 2010). By far, the hypothesis that has received the most attention posits that females that participate in EP matings gain "good genes" for their offspring, either by mating with a male superior to their social mate (Møller 1988, Hamilton 1990, Westneat et al. 1990, Birkhead and Møller 1992) or by choosing an EP sire with complementary genes (Kempenaers et al. 1999, Tregenza and Wedell 2000). This hypothesis predicts that extra-pair offspring (EPO) will be of higher quality than within-pair offspring (WPO; Griffith et al. 2002). However, despite years of extensive research, results are mixed at best, and the predictions of the "good genes" hypothesis have been borne out in $<50 \%$ of published papers (Akçay and Roughgarden 2007).

One potential explanation for this lack of consensus is that the benefits of EP mating are evident only in certain environments and not in others (Schmoll 2011). For example, EPO may inherit genes that give them a competitive advantage in the nest, allowing them to grow even when food is scarce. When resources are plentiful all nestlings will be well fed, irrespective of competitive ability, and EPO would appear to be of equal quality to WPO. In contrast, food limitation will force nestlings to compete for parental resources, so EPO can take full advantage of their better genes to outcompete their WPO half-siblings. Though this is just a hypothetical example, it illustrates how the environment can interact with the genetic makeup of offspring to either obscure or reinforce the benefit of EP mating to females. Despite the potential for environmental context to explain why benefits of EP mating are found only in some studies and not others, this hypothesis has been directly tested only a few times. In Coal Tits (Periparus ater), EPO had a higher probability of recruiting into the population than WPO, but only late in the season when overall rates of recruitment were lower
(Schmoll et al. 2005). The humoral immune response of Blue Tit (Cyanistes caeruleus) chicks was stronger for EPO, but only in artificially enlarged broods (Arct et al. 2013). Some studies have documented variation in relative fitness of EPO and WPO across different years of study, suggesting a potential role for environmental modulation of genetic benefits, but specific components of the environment that may have driven these patterns were not tested (Garvin et al. 2006, Forsman et al. 2008). These studies provide evidence for the environmental dependency of the good-genes hypothesis and demonstrate a context-dependent advantage to EPO in one or a few traits. However, they do not show an effect on fitness as a whole; a competitive advantage in growth might not equate to a competitive advantage in other important aspects such as predator evasion, for example. It is not readily apparent how to choose the appropriate proxy and/ or context to use to test fitness. What is needed is a proxy of fitness that integrates a large proportion of an individual's physiology and is predictive of fitness. Telomere length (TelL) might prove to be useful in this respect (Monaghan and Haussmann 2006).

Telomeres are the protective caps of eukaryotic chromosomes (Harley 1991). They shorten with each cell replication (Levy et al. 1992) as a consequence of oxidative stress (Epel et al. 2004) and upon the activation of the vertebrate stress response (Saretzki and Von Zglinicki 2002). Short TelL is associated with low survival in many species (reviewed in Haussmann and Marchetto 2010), is related to many pathologies (Blasco 2005), and is commonly used as a proxy for quality (Bauch et al. 2013, Le Vaillant et al. 2015, Bateson 2016, Costanzo et al. 2017). Specifically, early-life TelL is a better predictor of survival than late-life TelL (Heidinger et al. 2012). Because many physiological processes affect TelL, it can be used as an integrative measure of a key component of fitness (i.e. survival), and it allows us to generalize over many physiological aspects of fitness rather than focusing on only a few.

To look at the effects of EP status on chick quality and fitness, we used an existing brood manipulation conducted with the purpose of studying the determinants of early-life TelL (Belmaker 2016) and measured TelL, chick size, and probability of fledging. In Tree Swallows (Tachycineta bicolor), short TelL is associated with low survival (Haussmann et al. 2003, 2005, 2007) but not much else is known about telomere dynamics in this species (but see Belmaker 2016). In contrast, much is known about extrapair paternity (EPP): although it seems that EP matings in Tree Swallows are adaptive (Lombardo 1986, Lifjeld and Robertson 1992, Venier et al. 1993, Barber et al. 1996, Conrad et al. 2001, Whittingham and Dunn 2010), the nature of the benefit females get from extra-pair copulation (EPC) is still unclear (Whittingham and Dunn 2001), 
and there is evidence for benefits such as fertility assurance (Lombardo et al. 2002, 2004), brood diversification (Kempenaers et al. 1999, Whittingham et al. 2006, Stapleton et al. 2007, Dunn et al. 2009, Whittingham and Dunn 2010; but see Barber et al. 2005), and good genes (Kempenaers et al. 2001, Bitton et al. 2007, Whittingham and Dunn 2014, 2016). Given the uncertainty surrounding possible benefits of EP matings to Tree Swallows, looking at context dependence seems especially worthwhile, as it might help shed some light on some of the wide range of observed patterns.

\section{METHODS}

\section{Experimental Procedure}

To look at the effects of EP status on chick TelL we used an existing brood manipulation experiment conducted with the purpose of studying the determinants of early-life TelL (Belmaker 2016). The study site is a cattle grazing ground located in Harford, New York $\left(42.44^{\circ} \mathrm{N}, 76.23^{\circ} \mathrm{W}\right)$, with $\sim 130$ nest boxes mounted on fence posts $\sim 1.5 \mathrm{~m}$ from the ground. For 3 breeding seasons from 2012 to 2014 we enlarged broods and cross-fostered chicks between control and enlarged broods of Tree Swallows. Each season we monitored the nest boxes daily to detect the day the first egg was laid (clutch initiation date). Clutch completion date was determined as the day the last egg was laid. Once chicks hatched we matched broods for hatch date, female age, and clutch size. We were able to age adult females because Tree Swallow females show delayed-plumage maturation, in which females in their first breeding attempt (SY) are brown-green in color, and older females have the iridescent blue color characteristic of Tree Swallows (Hussell 1983). SY males look like older females. All brown females were given an age of 1 . Older females were aged exactly based on previous capture data, and if that was not available we assigned them the minimum age (2 for the first encounter and increasing incrementally after that). Unbanded males were assigned a minimum age of 1 . When all chicks hatched, usually between the ages of 0 and 2 days, we randomly swapped as near as possible to half of the chicks between the 2 broods and added chicks to the brood designated as enlarged (either 2 or 3 chicks in the vast majority of cases). Chicks for the brood enlargement came from a nest not participating in the experiment and were of the same age as manipulated nests. We did not use a brood reduction treatment as well to obtain sufficient nests that match for all the above criteria. We could not ascertain which chick hatched from which egg so could not control for quality differences between EP and WP chicks due to maternal effects (e.g., Magrath et al. 2009). However, in Tree Swallows maternal effects do not seem to be an important cause for such differences (Barber and Robertson 2007). Final brood sizes averaged $5.07 \pm$
0.67 for control broods and $8.05 \pm 0.86$ for enlarged broods (mean \pm SD). We then followed the nesting attempt to completion. We measured the chicks every 4 days for mass, wing length, and head-plus-bill length. These 3 morphometric measures were combined into one size measure using a principal component analysis with the princomp function in $R$ ( $R$ Core Team 2015). All 3 measures showed a linear negative relationship to PC1 but, as principal component signs are arbitrary, we reversed the sign and used PC1 as our measure of chick size. For all measures an increasing PC1 reflects larger size. Only the fourth morphometric measure was used in our analysis. On day 12, we took a blood sample for both TelL measurement and genotyping. After day 12 the nest was not disturbed until all chicks fledged. Once the last chick fledged any dead chicks that remained in the box were noted and collected for genotyping. Females were caught during incubation and males soon after hatching. We were able to catch $97 \%$ of the females and $28 \%$ of the males nesting in our nest box population. At capture a blood sample for genotyping was taken by a small puncture to the brachial vein and collecting approximately $75-150 \mu \mathrm{L}$ of whole blood into a heparinized capillary tube. Half of the blood was mixed with lysis buffer for genotyping and the other half was put in an empty micro-centrifuge tube and kept on ice until further processing in the lab. At the end of the day the chilled telomere samples were spun down at 3,500 rpm for $5 \mathrm{~min}$ and the plasma was removed. One milliliter of NBS buffer (90\% new-born calf serum and $10 \%$ DMSO) was added and mixed with the red blood cells (RBCs). The samples were then frozen slowly and kept at $-80^{\circ} \mathrm{C}$ for storage until further analysis. Only the first nesting attempt of the season was used and no females were used more than once.

\section{Telomere Length Analysis}

Telomeres were measured using the telomere restriction fragment assay (TRF; Kimura et al. 2010). DNA was extracted using an isopropanol-ethanol extraction with a Gentra Purgene extraction kit (Qiagen, Hilden, Germany) for the extraction of high-quality high-yield DNA. DNA integrity was checked on a $0.8 \%$ agarose gel made with $0.5 \mathrm{X}$ TBE run for $1 \mathrm{hr}$ in $120 \mathrm{~V}$. Genomic DNA was digested by incubating $10 \mu \mathrm{g}$ of DNA for at least $16 \mathrm{hr}$ at $37^{\circ} \mathrm{C}$ with a combination of 3 restriction enzymes (RsaI, HaeIII, and HinfI). Samples were then frozen until further processing. When ready for processing, samples were thawed at $37^{\circ} \mathrm{C}$ and run on a $0.8 \%$ agarose gel in a pulsedfield gel electrophoresis rig for $19 \mathrm{hr}(3 \mathrm{~V} / \mathrm{cm}, 0.5 \mathrm{~s}$ initial switch time, $7 \mathrm{~s}$ final switch time) alongside 3 lanes of $1 \mathrm{~kb}$ extension ladder from Invitrogen and 2 standard lanes made of either domestic chicken (Gallus gallus domesticus) blood or Tree Swallow blood. After drying, the gel was hybridized overnight with a radioactive probe 
TABLE 1. The correlation coefficients $(r)$ between 12 metrics from the TelL distribution: mean TelL, skew, kurtosis, and the 10th to 90th percentiles (P10 to P90, respectively). In all cases $P<0.001$. The row in bold shows the PCA loadings for PC1, which explained $88.5 \%$ of the variation and was thus the only PC used in the analyses for this paper.

\begin{tabular}{|c|c|c|c|c|c|c|c|c|c|c|c|c|}
\hline PC1 loadings & $\begin{array}{c}\text { Mean } \\
\mathbf{0 . 2 5}\end{array}$ & $\begin{array}{l}\text { Skew } \\
-\mathbf{0 . 0 8}\end{array}$ & $\begin{array}{c}\text { Kurtosis } \\
-\mathbf{0 . 4 9}\end{array}$ & $\begin{array}{l}\text { P10 } \\
\mathbf{0 . 0 8}\end{array}$ & $\begin{array}{l}\text { P20 } \\
\mathbf{0 . 1 4}\end{array}$ & $\begin{array}{l}\text { P30 } \\
\mathbf{0 . 1 8}\end{array}$ & $\begin{array}{l}\text { P40 } \\
\mathbf{0 . 2 1}\end{array}$ & $\begin{array}{l}\text { P50 } \\
\mathbf{0 . 2 4}\end{array}$ & $\begin{array}{l}\text { P60 } \\
\mathbf{0 . 2 7}\end{array}$ & $\begin{array}{l}\text { P70 } \\
\mathbf{0 . 3 1}\end{array}$ & $\begin{array}{l}\text { P80 } \\
\mathbf{0 . 3 7}\end{array}$ & $\begin{array}{l}\text { P90 } \\
\mathbf{0 . 4 9}\end{array}$ \\
\hline Mean & 1 & & & & & & & & & & & \\
\hline Skew & -0.88 & 1 & & & & & & & & & & \\
\hline Kurtosis & 0.84 & 0.95 & 1 & & & & & & & & & \\
\hline P10 & 0.72 & -0.44 & -0.33 & 1 & & & & & & & & \\
\hline P20 & 0.87 & -0.63 & -0.52 & 0.95 & 1 & & & & & & & \\
\hline P30 & 0.92 & -0.72 & -0.61 & 0.88 & 0.99 & 1 & & & & & & \\
\hline P40 & 0.95 & -0.79 & -0.68 & 0.83 & 0.96 & 0.99 & 1 & & & & & \\
\hline P50 & 0.97 & -0.83 & -0.74 & 0.78 & 0.93 & 0.98 & 0.99 & 1 & & & & \\
\hline P60 & 0.98 & -0.87 & -0.79 & 0.74 & 0.89 & 0.95 & 0.98 & 0.99 & 1 & & & \\
\hline P70 & 0.99 & -0.91 & -0.84 & 0.68 & 0.85 & 0.91 & 0.95 & 0.97 & 0.99 & 1 & & \\
\hline P80 & 0.98 & -0.93 & -0.9 & 0.61 & 0.77 & 0.84 & 0.89 & 0.93 & 0.96 & 0.99 & 1 & \\
\hline P90 & 0.92 & -0.9 & -0.94 & 0.46 & 0.63 & 0.71 & 0.76 & 0.81 & 0.86 & 0.9 & 0.96 & 1 \\
\hline
\end{tabular}

$($ CCCTAA $\times 4)$ that anneals to the single-stranded overhang at the end of the telomere. The following day the gel was washed with a $0.5 \mathrm{X}$ SSC solution and placed on a phosphor screen (Amersham Bio-sciences, Buckinghamshire, UK) for at least 2 days. The screen was then visualized using a Storm 540 Variable Mode Imager (Amersham Biosciences).

The resulting gel image is a "smear" representing the TelL distribution for any given individual (Kimura et al. 2010). Measurements on this distribution used ImageJ (Version 2.0.0-rc-34/1.50a; Schindelin et al. 2012), an open-source image processing software. Optical density values (OD) were measured by running a line selection through the center of each lane. OD values directly measure the number of telomere molecules of the length indicated by the position on the gel. The size of each telomere fragment at a given pixel location down the lane (KBi) was measured by fitting a cubic polynomial to the central ladder lane of each gel. We used an analysis window between 1.636 and $40 \mathrm{~kb}$ (the 2 outmost visible size markers). Background was subtracted from all OD measurements and was estimated by measuring a horizontal line placed just below the lowest size marker.

This procedure produces a distribution of TelLs per individual rather than just one measurement that summarizes that distribution, because each cell and each chromosome has a telomere of a different length (Kimura et al. 2010, Nussey et al. 2014). To estimate TelL we measured a few key metrics from each distribution: the mean TelL, the skew and kurtosis, and the 10th to 90th deciles of the distribution. These metrics were chosen to roughly trace the shape of the TelL distribution. Because all of these metrics were correlated we combined them using a principal component analysis (PCA). This PCA was conducted using the princomp function from the stats package in R (version 3.2.1; R Core Team 2015). We used only the first principal component score (PC1) for all analyses because, by itself, it explained $88.5 \%$ of the variation. Table 1 details the correlation coefficient between the metrics and the loadings for the PCA.

\section{Genotyping and Sexing}

We extracted DNA from RBCs stored in lysis buffer or from dead nestlings using the Qiagen DNeasy Blood and Tissue kit. Following extraction, we amplified 9 microsatellite loci (Stenzler 2001, Makarewich et al. 2009) using multiplex polymerase chain reaction (PCR). PCR conditions were as follows: an initial denaturation step of $2 \mathrm{~min}$ at $95^{\circ} \mathrm{C}$, followed by 35 cycles of $30 \mathrm{~s}$ of denaturation at $95^{\circ} \mathrm{C}, 60 \mathrm{~s}$ of annealing at either $56^{\circ} \mathrm{C}$ or $58^{\circ} \mathrm{C}$, and $60 \mathrm{~s}$ of extension at $72^{\circ} \mathrm{C}$. A final elongation step was thereafter performed for $30 \mathrm{~min}$ at $72^{\circ} \mathrm{C}$. We used Geneious (version 9.0.5; Kearse et al. 2012) to call alleles and CERVUS (version 3.0; Kalinowski et al. 2007) to assign parentage to nestlings. The social mother was assumed to be the genetic mother of all nestlings in the female's original nest. Any instances of single-locus mismatches between mothers and offspring were attributed to genotyping error. A male was identified as the genetic father of a nestling if one of the following conditions was met: (1) the male mismatched the nestling at no more than one locus and was identified by CERVUS as the most likely sire with $>95 \%$ confidence; or (2) no male was assigned paternity with $>95 \%$ confidence, but the male mismatched the nestling at no more than one locus and was the social father at the nest (i.e. the male's genotype was consistent with the male being the genetic sire). We determined the sex of each nestling using a P2/P8 sexing protocol with a HaeIII digest similar to that described in Whittingham and Dunn (2000). We could not identify the EP status of the chick in 182 cases $(\sim 44 \%)$. We could not identify the genetic father of 262 chicks ( 63\%). 


\section{Statistical Analysis}

All analyses were carried out in R (version 3.2.1; R Core Team 2015). We used linear and generalized linear mixedeffect models. We used the lmer and glmer functions from the lme4 package (version 1.1-11; Bates et al. 2013). We built models for 3 response variables: TelL, chick size, and probability of fledging. In each model we added EP status, experimental group, and their interaction as fixed effects. To control for the cross-fostering procedure, we added both natal and rearing broods as random intercepts in our model. In addition, the identity of the genetic father was also added as a random effect. Only one sample was taken for TelL (on day 12), so the TelL model included only data from chicks that survived to the last measurement. Similarly, as only the last morphometric measure was used, the size model includes only chicks that survived to day 12. For a subset of samples we were not able to measure TelL, either because we could not get enough blood or the protocol failed for some reason. For this reason the sample size for the morphometric model is larger than the one for TelL. The model for the probability of fledging included chicks that died before a TelL sample was taken.

For each response variable we fit all 5 possible models (2 main terms and their interaction, 2 main terms with no interaction, each main term alone, and an intercept-only model). We then examined the $\mathrm{AIC}_{\mathrm{c}}$ (Akaike information criteria corrected for small sample sizes) and the weight $\left(w_{i}\right)$ for each model to choose the best one. To aid in model selection in cases where the best model is not clearly evident $(\Delta \mathrm{AIC}<2)$, we tested the significance of specific terms using a likelihood ratio test (LRT) using the anova function in R. Estimates and standard errors were calculated using the summary function and confidence intervals for plots were calculated using the Wald method in the effects package (Version 4.0-1; Fox 2003).

\section{RESULTS}

In total, 39 paired brood manipulations were conducted (16 in 2012, 9 in 2013, and 14 in 2014) and 416 chicks were used in the experiment, 154 of which could be assigned paternity status. About half of the broods did not contain EP chicks and for the rest the ratio of EP chicks ranged uniformly across the entire range from 0 to 1 . At the start of the experiment there was no difference in size between chicks in control and enlarged broods (control: $-15.24 \pm$ 1.07, enlarged: $-15.24 \pm 1.05 ; n=154, t=1.37$, df $=$ 114.56, $P=0.17$ ) and between WPO and EPO (WPO: $-15.48 \pm 0.98$, EPO: $-15.34 \pm 0.98 ; n=154, \mathrm{df}=138.13, t$ $=-1.78, P=0.08)$. By day 12 chicks in enlarged broods were substantially smaller $\left(n=122, \beta=-7.18 \pm 1.961, \chi^{2}\right.$ $=10.65, \mathrm{df}=24.82, P=0.001)$. Additionally, chicks in enlarged broods had a lower probability of fledging than chicks in control broods $\left(n=154, \beta=-5.08 \pm 2.58, \chi^{2}=\right.$ 11.78, $P<0.001)$.

\section{Telomere Length}

The models with either experimental group or EP status alone and the model with both main effects and their interaction came out as similarly likely, and were all within one $\mathrm{AIC}_{\mathrm{c}}$ point of one another (Table 2). Likelihood ratio tests for each term show that the interaction of EP status and experimental group $\left(n=112, \beta=-0.9 \pm 1.27, \chi^{2}=\right.$ $0.56, \mathrm{df}=80.25, P=0.46$; Figure 1$)$ and EP status $(n=112$, $\beta=-0.96 \pm 0.73, \chi^{2}=1.55, \mathrm{df}=98.85, P=0.21$; Figure 1$)$ are not significant but experimental group is $(n=112, \beta=$ $-1.41 \pm 0.61, \chi^{2}=4.75, \mathrm{df}=18.35, P=0.03$; Figure 1 ).

\section{Size}

$\mathrm{AIC}_{\mathrm{c}}$ values for the size models show that the model with experimental group alone and the model with both experimental group and EP status share similar $\mathrm{AIC}_{\mathrm{c}}$ scores, with the former having a slightly lower $\mathrm{AIC}_{\mathrm{c}}$ (Table 2). However, based on the likelihood ratio tests only experimental group has a significant effect on chick size on day 12 (experimental group: $n=122, \beta=-7.18 \pm 1.961, \chi^{2}$ $=10.65, \mathrm{df}=24.82, P=0.001$; EP status: $n=122, \beta=-1.19$ $\pm 1.47, \chi^{2}=0.52, \mathrm{df}=34.77, P=0.47$; Figure 2).

\section{Probability of Fledging}

The model selection table for models of the probability of fledging give the full model and the model excluding the interaction a similar $\mathrm{AIC}_{\mathrm{c}}$ value, with the latter being the most likely model (Table 2). The interaction of EP status and experimental group was not significant based on the likelihood ratio test $\left(n=154, \beta=-2.14 \pm 2.34, \chi^{2}=0.93, P\right.$ $=0.33$; Figure $3 \mathrm{~A})$. EPO have higher fledging rates than WPO $\left(n=154, \beta=-3.01 \pm 1.35, \chi^{2}=9.31, P=0.002\right.$; Figure $3 \mathrm{~A}$ ) in total but a visual inspection of the probability of fledging in each group (Figure 3A) suggests that this effect is driven by chicks in enlarged broods. With tests conducted for each group separately a significant effect on the probability of fledging was obtained only in enlarged broods (control broods: $n=78, \beta=-9.85 \pm 5.11, \chi^{2}=$ 2.30, $P=0.13$; enlarged broods: $n=76, \beta=-2.31 \pm 0.98$, $\chi^{2}=8.01, P=0.005$; Figure $\left.3 \mathrm{~B}\right)$.

\section{DISCUSSION}

In this study we tested the context-dependent version of the good genes hypothesis (Schmoll 2011), which predicts that differences in quality between EPO and WPO will only be apparent in stressful environments. The experimental treatment succeeded in creating a stressful environment for the chicks-chicks in enlarged broods were smaller, had a lower probability of fledging, and had shorter telomeres than chicks in control broods (due to the 
TABLE 2. The model selection table for 3 response variables (telomere length, chick size, and the probability of fledging). The tested models are combinations of 3 fixed effects: experimental group $(G)$, extra-pair status $(S)$, and their interaction ( $\left.G^{*} S\right)$. The terms included in each model are marked by a " + " in the appropriate column. For each model we provide the degrees of freedom (df), the log-likelihood (logLik), the Akaike information criteria corrected for small sample sizes $\left(A_{1} C_{c}\right)$, the difference in $A_{C} C_{c}$ value of each model from the model with the lowest $\mathrm{AIC}_{\mathrm{c}}$ score $(\triangle \mathrm{AIC})$, and the weight $\left(w_{i}\right)$ of each model (its relative likelihood).

\begin{tabular}{|c|c|c|c|c|c|c|c|c|}
\hline Model & G & $S$ & $\mathrm{G}^{*} \mathrm{~S}$ & $d f$ & logLik & $\mathrm{AlC}_{\mathrm{c}}$ & $\Delta \mathrm{AlC}_{\mathrm{c}}$ & $w_{i}$ \\
\hline \multicolumn{9}{|c|}{ Telomere length } \\
\hline 1 & + & + & + & 8 & -284.50 & 586.40 & 0.00 & 0.38 \\
\hline 2 & + & + & & 7 & -285.90 & 586.88 & 0.48 & 0.30 \\
\hline 3 & + & & & 6 & -287.32 & 587.44 & 1.04 & 0.22 \\
\hline 4 & & + & & 6 & -288.64 & 590.09 & 3.69 & 0.06 \\
\hline 5 & & & & 5 & -290.18 & 590.93 & 4.53 & 0.04 \\
\hline \multicolumn{9}{|c|}{ Chick size } \\
\hline 1 & + & & & 6 & -408.13 & 828.99 & 0.00 & 0.61 \\
\hline 2 & + & + & & 7 & -407.87 & 830.73 & 1.74 & 0.26 \\
\hline 3 & + & + & + & 8 & -407.47 & 832.21 & 3.22 & 0.12 \\
\hline 4 & & & & 5 & -413.53 & 837.58 & 8.59 & 0.01 \\
\hline 5 & & + & & 6 & -413.20 & 839.12 & 10.13 & 0.00 \\
\hline \multicolumn{9}{|c|}{ Probability of fledging } \\
\hline 1 & + & + & & 6 & -70.98 & 154.52 & 0.00 & 0.64 \\
\hline 2 & + & + & + & 7 & -70.51 & 155.79 & 1.26 & 0.34 \\
\hline 3 & + & & & 5 & -75.63 & 161.67 & 7.15 & 0.02 \\
\hline 4 & & + & & 5 & -76.86 & 164.13 & 9.61 & 0.01 \\
\hline 5 & & & & 4 & -81.58 & 171.44 & 16.91 & 0.00 \\
\hline
\end{tabular}

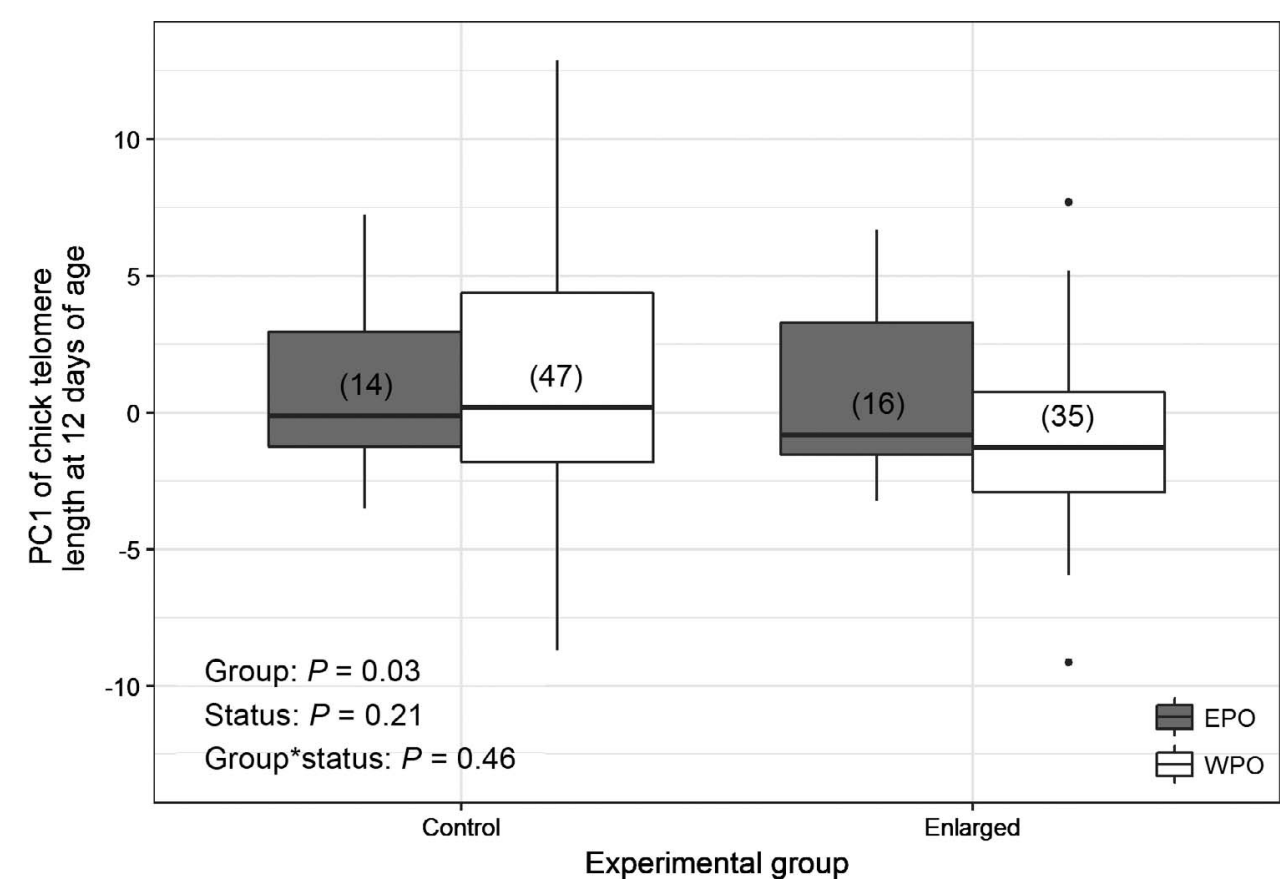

FIGURE 1. Effect of experimental group (Group), extra-pair status (Status), and their interaction (Group*Status) on the telomere length of 12-day-old chicks. Telomere length is the PC1 from a principal component analysis on 12 metrics from the telomere length distribution (see Methods). Light and dark boxes are for within-pair (WPO) and extra-pair (EPO) chicks, respectively, growing up in control (left side) or enlarged (right side) broods. The central line represents the median, the 2 "hinges" are the first and third quartiles, and the "whiskers" are \pm 1.5 times the interquartile range. Dots represent outliers. The number in parentheses inside each box is the sample size for each group. $P$ values were calculated using likelihood ratio tests. 


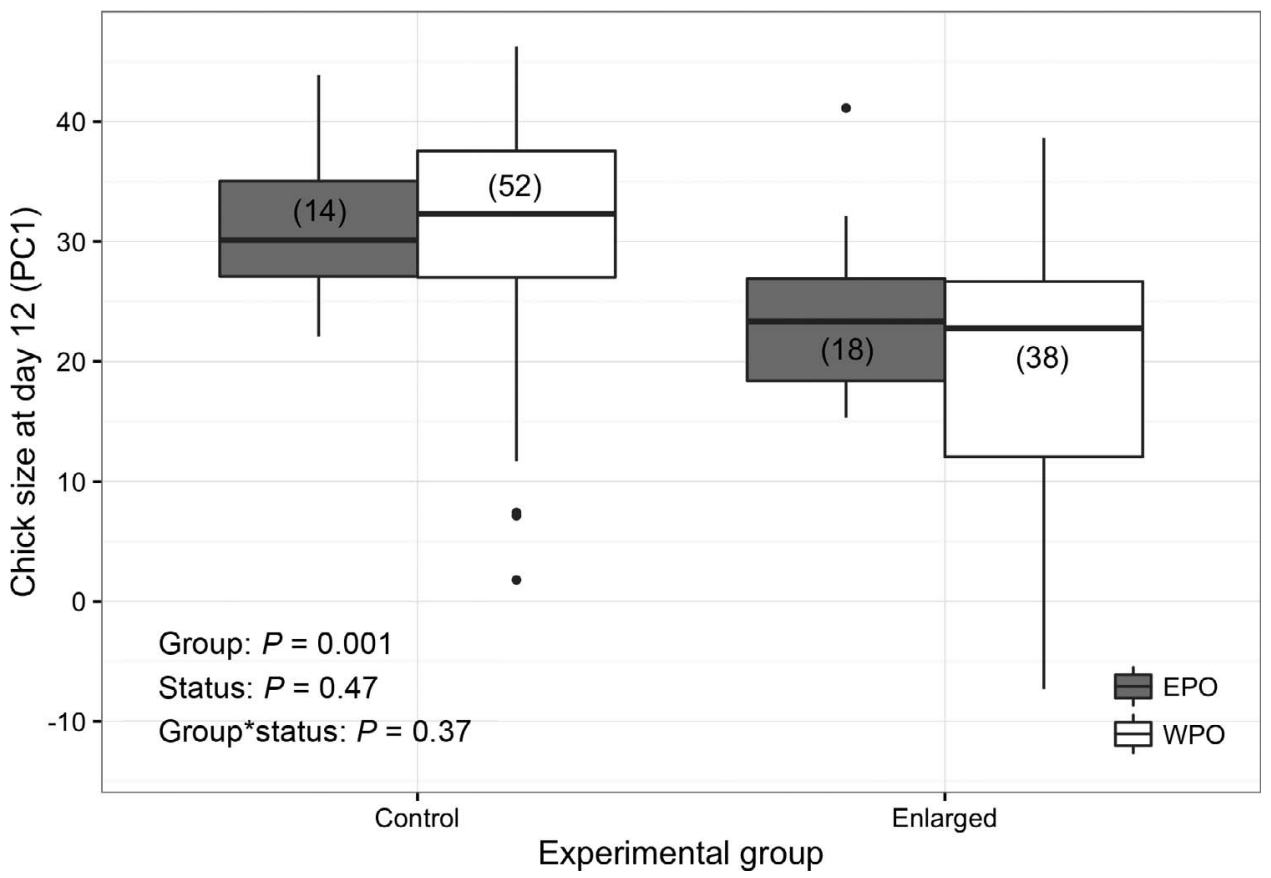

FIGURE 2. Effect of experimental group (Group), extra-pair status (Status), and their interaction (Group*Status) on the size of 12-dayold chicks. Chick size is the PC1 from a principal component analysis on chick mass, wing length, and head-plus-bill length (see Methods). Light and dark boxes are for within-pair (WPO) and extra-pair (EPO) chicks, respectively, growing up in control (left side) or enlarged (right side) broods. The central line represents the median, the 2 "hinges" are the first and third quartiles, and the "whiskers" are \pm 1.5 times the interquartile range. Dots represent outliers. The number in parentheses inside each box is the sample size for each group. $P$ values were calculated using likelihood ratio tests.

stress induced by the treatment). EP status and its interaction with experimental group were among the models with the lowest $\mathrm{AIC}_{\mathrm{c}}$ scores for TelL and size, but other more parsimonious models were just as likely $\left(\Delta \mathrm{AIC}_{\mathrm{c}}<2\right)$. Additionally, likelihood ratio tests done to corroborate the AIC model selection do not support EP status or its interaction with experimental group as significant factors in determining either chick TelL or size. EP status was an important predictor of the probability of fledging. Even though the interaction of EP status and experimental group was not significant in the full model, a visual inspection of the plot suggests that this effect is mainly present in enlarged broods (Figure 3A). In the separate per-group analysis we also found that EPO have an advantage over WPO but only in enlarged broods. This pattern for the probability of fledging supports the idea that EPO are of higher quality than WPO-EPO had a higher probability of fledging - and that this advantage is context-dependent-the effect of EP status was driven by chicks in enlarged broods. However, as a whole, these results are not very convincing: the predicted pattern was borne out only in one of three metrics and even with the probability of fledging appears only in a separate analysis per group.

So why do we not find stronger evidence for the goodgenes hypothesis and for context dependence? First, chicks in this study were measured at 12 days of age to minimize the risk of premature fledging. However, undisturbed Tree Swallow chicks do not fledge until 21 days of age, on average. Thus, the chicks still had almost half their nesting lives before them after we took the sample. Chicks that did not survive to that age could not be sampled, even if found dead in the nest. It is possible that lower-quality chicks were overrepresented among these early-dying chicks, and that this is the cause for the lack of effect on TelL and size we observed. It is further possible that the chicks were sampled too early in development to show an effect. Possibly, had we measured the chicks closer to fledging, we might have found a stronger effect of EP status. We have no way of testing for this effect, but future studies should allow enough time in the stressful environment to make sure an effect, if it exists, would be able to manifest itself.

Second, TelL or size might not have been the proper metric in this context. Perhaps, if we could have measured TelL twice, the rate of telomere shortening would have been better to measure than actual TelL (e.g., Boonekamp et al. 2014, Watson et al. 2015). Regardless, any study of the fitness impact of variation in a trait can fail to find an effect of that trait in a large number of contexts. This never means that the trait has no relevance to fitness, only that it does not have the fitness effect appropriate to the contexts tested. In this study we measured size, TelL and the 

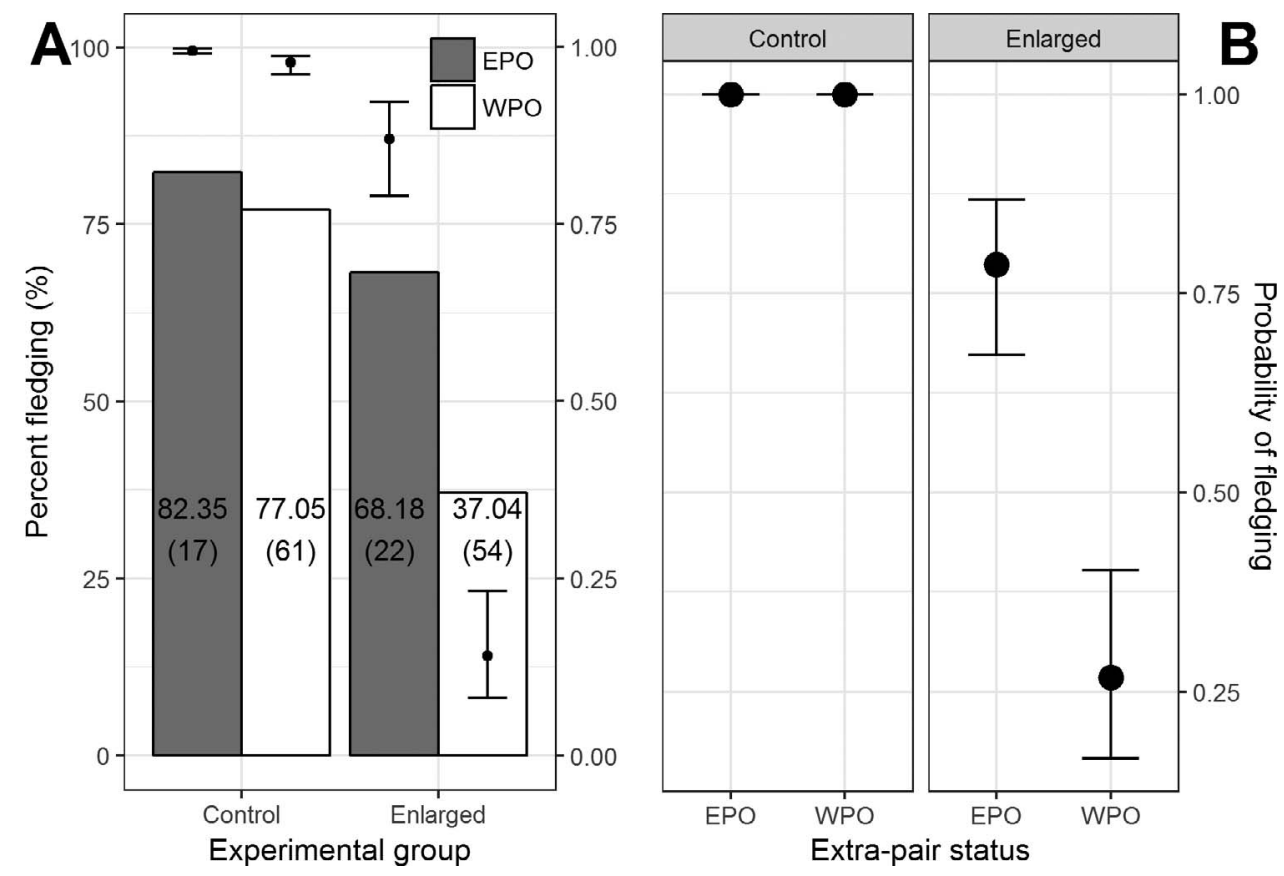

FIGURE 3. Percentage of chicks fledged and the estimated probability of fledging from a generalized linear mixed model. (A) Percentage of WPO (light bars) and EPO (dark bars) chicks that fledged from control (left) and enlarged (right) broods. Number in the lower part of each bar is the percentage fledged and the sample size in parentheses. Points and 95\% confidence intervals superimposed show the estimates from the full model including experimental group, EP status, and their interaction. (B) Estimated effects and 95\% confidence intervals of EP status on the probability of fledging when the model was run in control (left) or enlarged (right) groups separately.

probability of fledging. Our results show that TelL and size were not affected by EP status while the probability of fledging was affected (albeit weakly). This shows how one fitness proxy can show the hypothesized pattern while another does not. Our ability to choose the proper metric and context in which to test EP effects on fitness is of paramount importance. Previous studies that reported a context-dependent benefit of EPP in birds used various metrics as a proxy for fitness, and various contexts to test the effect of EP status on the chosen proxy (Schmoll et al. 2005, Garvin et al. 2006, Forsman et al. 2008, Schmoll 2011, Arct et al. 2013). The proxy and context chosen will ultimately determine if a given study can or cannot detect the hypothesized effect, but choosing them is not an easy task-there is no a priori way of knowing whether a given metric and context are appropriate. If this is true, then some studies, which happen to choose an appropriate fitness proxy and context, will find a benefit to female EPC, while others will not, as we see in the literature (Akçay and Roughgarden 2007).

Just as it is hard for the biologist to anticipate what fitness-relevant traits will be important in any given context, it must be very difficult for females to evaluate the traits of a potential mate when making mate choice decisions. "Good genes" are to be sought for both WP and EP mates, but what makes a "good gene" is dependent on the context in which it is expressed (Hasson and Stone 2010, Schmoll 2011). From the time and place where a female must make mating decisions, there is no basis for predicting the conditions that either the female or the female's offspring will find themselves in the future, and the female must choose based on a number of sexual signals (e.g., Whittingham and Dunn 2016), which only correlate with fitness on average. Thus, it is not surprising that mate choice does not always seem to yield a benefit (Kirkpatrick and Barton 1997, Møller and Alatalo 1999, Arnqvist and Kirkpatrick 2005). The ability of females to choose the best mate is also limited by the array of mates available to her in any given window of time (cf. Ferretti and Winkler 2009) further limiting our ability to detect the benefits to mate choice.

Lastly, it is definitely a possibility that we could not find a context-dependent benefit to EPC because there is none (Forstmeier et al. 2014). Even though this is a distinct possibility there is much evidence that females do receive some form of benefit from EPC, even if the nature of the benefit is unclear (Whittingham and Dunn 2001).

To summarize, EPO in enlarged broods in this study had a higher probability of fledging than did WPO. We could not detect an advantage to EPO in either TelL or body size, possibly because we sampled too early, these are not the proper metrics or context, we lack the ability to detect such benefits, or there are no such benefits at all. 


\section{ACKNOWLEDGMENTS}

We would like to acknowledge Irby Lovette, Laura Stenzler, Bronwyn Butcher, Steve Bogdanowitz, Kim Sparks, and Teresa Pegan for help with lab work; Aaron Bhole and many undergraduate students for help with fieldwork. We would also like to thank André Dhondt, Mike Webster, and 3 anonymous referees for constructive comments during the preparation of this manuscript.

Funding statement: This work was supported by the John Weber endowment and the Athena fund at the Cornell Lab of Ornithology; the Department of Ecology and Evolutionary Biology and the Andrew W. Mellon Student research Grants at Cornell University; Sigma Xi; the Society for Integrative and comparative Biology; the American Ornithologists' Union; and NSF LTREB grants (DEB-0717021 and DEB 1242573 to DWW).

Ethics statement: Data collection was done under federal collecting permit (M8757670-0) given to David Winkler. All procedures performed in this study were in accordance with the ethical standards of Cornell University.

Author contributions: (1) AB formulated the questions; (2) $\mathrm{AB}$ collected field data; (3) AB, $\mathrm{KKH}$, and RAG preformed the laboratory analysis; (4) AB wrote the paper with substantial editing from $\mathrm{KKH}$ and DWW and (5) AB, MFH, and DWW contributed substantial materials, resources, and funding.

\section{LITERATURE CITED}

Akçay, E., and J. Roughgarden (2007). Extra-pair paternity in birds: Review of the genetic benefits. Evolutionary Ecology Research 9:855-868.

Arct, A., S. M. Drobniak, E. Podmokła, L. Gustafsson, and M. Cichoń (2013). Benefits of extra-pair mating may depend on environmental conditions-an experimental study in the blue tit (Cyanistes caeruleus). Behavioral Ecology and Sociobiology 67:1809-1815.

Arnqvist, G., and M. Kirkpatrick (2005). The evolution of infidelity in socially monogamous passerines: The strength of direct and indirect selection on extrapair copulation behavior in females. The American Naturalist 165:S26-S37.

Barber, C. A., and R. J. Robertson (2007). Timing of copulations and the pattern of paternity in relation to laying order in Tree Swallows Tachycineta bicolor. Journal of Avian Biology 38: 249-254.

Barber, C. A., M. J. Edwards, and R. J. Robertson (2005). A test of the genetic compatibility hypothesis with Tree Swallows, Tachycineta bicolor. Canadian Journal of Zoology 83:955-961.

Barber, C. A., R. J. Robertson, and P. T. Boag (1996). The high frequency of extra pair paternity in Tree Swallows is not an artifact of nestboxes. Behavioral Ecology and Sociobiology 38:425-430.

Bates, D., M. Maechler, B. Bolker, and S. Walker (2013). Ime4: Linear mixed-effects models using Eigen and S4. R package version 1.

Bateson, M. (2016). Cumulative stress in research animals: Telomere attrition as a biomarker in a welfare context? BioEssays 38:201-212.

Bauch, C., P. H. Becker, and S. Verhulst (2013). Telomere length reflects phenotypic quality and costs of reproduction in a long-lived seabird. Proceedings of the Royal Society B: Biological Sciences 280:20122540.

Belmaker, A. (2016). The role of telomere length in Tree Swallow life history and behavior. Ph.D. dissertation, Cornell University, Ithaca, NY, USA.

Birkhead, T. R., and A. P. Møller (1992). Sperm Competition in Birds: Evolutionary Causes and Consequences. Academic Press, San Diego, CA, USA.

Bitton, P.-P., E. L. O'Brien, and R. D. Dawson (2007). Plumage brightness and age predict extrapair fertilization success of male Tree Swallows, Tachycineta bicolor. Animal Behaviour 74:1777-1784.

Blasco, M. A. (2005). Telomeres and human disease: Ageing, cancer and beyond. Nature Reviews Genetics 6:611-622.

Boonekamp, J. J., G. A. Mulder, H. M. Salomons, C. Dijkstra, and S. Verhulst (2014). Nestling telomere shortening, but not telomere length, reflects developmental stress and predicts survival in wild birds. Proceedings of the Royal Society of London B: Biological Sciences 281:20133287.

Burke, T., N. B. Davies, M. W. Bruford, and B. J. Hatchwell (1989). Parental care and mating behaviour of polyandrous Dunnocks Prunella modularis related to paternity by DNA fingerprinting. Nature 338:249-251.

Colwell, M. A., and L. W. Oring (1989). Extra-pair mating in the Spotted Sandpiper: A female mate acquisition tactic. Animal Behaviour 38:675-684.

Conrad, K. F., P. V. Johnston, C. Crossman, B. Kempenaers, R. J. Robertson, N. T. Wheelwright, and P. T. Boag (2001). High levels of extra-pair paternity in an isolated, low-density, island population of Tree Swallows (Tachycineta bicolor). Molecular Ecology 10:1301-1308.

Costanzo, A., M. Parolini, G. Bazzi, L. Khoriauli, M. Santagostino, C. D. Possenti, A. Romano, S. G. Nergadze, D. Rubolini, E. Giulotto, and N. Saino (2017). Brood size, telomere length, and parent-offspring color signaling in Barn Swallows. Behavioral Ecology 28:204-211.

Dunn, P. O., J. T. Lifjeld, and L. A. Whittingham (2009). Multiple paternity and offspring quality in Tree Swallows. Behavioral Ecology and Sociobiology 63:911-922.

Epel, E. S., E. H. Blackburn, J. Lin, F. S. Dhabhar, N. E. Adler, J. D. Morrow, and R. M. Cawthon (2004). Accelerated telomere shortening in response to life stress. Proceedings of the National Academy of Sciences USA 101:17312-17315.

Ferretti, V., and D. W. Winkler (2009). Polygyny in the Tree Swallow Tachycineta bicolor: A result of the cost of searching for an unmated male. Journal of Avian Biology 40:289-295.

Forsman, A. M., L. A. Vogel, S. K. Sakaluk, B. G. Johnson, B. S. Masters, L. S. Johnson, and C. F. Thompson (2008). Female House Wrens (Troglodytes aedon) increase the size, but not immunocompetence, of their offspring through extra-pair mating. Molecular Ecology 17:3697-3706.

Forstmeier, W., S. Nakagawa, S. C. Griffith, and B. Kempenaers (2014). Female extra-pair mating: Adaptation or genetic constraint? Trends in Ecology \& Evolution 29:456-464.

Fox, J. (2003). Effect displays in $\mathrm{R}$ for generalised linear models. Journal of Statistical Software 8:1-27.

Garvin, J. C., B. Abroe, M. C. Pedersen, P. O. Dunn, and L. A. Whittingham (2006). Immune response of nestling warblers varies with extra-pair paternity and temperature. Molecular Ecology 15:3833-3840. 
Griffith, S. C., I. P. F. Owens, and K. A. Thuman (2002). Extra pair paternity in birds: A review of interspecific variation and adaptive function. Molecular Ecology 11:2195-2212.

Hamilton, W. D. (1990). Mate choice near or far. American Zoologist 30:341-352.

Harley, C. B. (1991). Telomere loss: Mitotic clock or genetic time bomb? Mutation Research 256:271-282.

Hasson, O., and L. Stone (2010). Why do females have so few extra-pair offspring? Behavioral Ecology and Sociobiology 65: 513-523.

Haussmann, M., and N. Marchetto (2010). Telomeres: Linking stress and survival, ecology and evolution. Current Zoology 56:714-727.

Haussmann, M. F., D. W. Winkler, C. E. Huntington, I. C. T. Nisbet, and C. M. Vleck (2007). Telomerase activity is maintained throughout the lifespan of long-lived birds. Experimental Gerontology 42:610-618.

Haussmann, M. F., D. W. Winkler, K. M. O'Reilly, C. E. Huntington, I. C. T. Nisbet, and C. M. Vleck (2003). Telomeres shorten more slowly in long-lived birds and mammals than in short-lived ones. Proceedings of the Royal Society B: Biological Sciences 270:1387-1392.

Haussmann, M. F., D. W. Winkler, and C. M. Vleck (2005). Longer telomeres associated with higher survival in birds. Biology Letters 1:212-214.

Heidinger, B. J., J. D. Blount, W. Boner, K. Griffiths, N. B. Metcalfe, and P. Monaghan (2012). Telomere length in early life predicts lifespan. Proceedings of the National Academy of Sciences USA 109:1743-1748.

Hussell, D. J. T. (1983). Age and plumage color in female Tree Swallows. Journal of Field Ornithology 54:312-318.

Jeffreys, A. J., V. Wilson, and S. L. Thein (1985). Hypervariable "minisatellite" regions in human DNA. Nature 314:67-73.

Kalinowski, S. T., M. L. Taper, and T. C. Marshall (2007). Revising how the computer program CERVUS accommodates genotyping error increases success in paternity assignment. Molecular Ecology 16:1099-1106.

Kearse, M., R. Moir, A. Wilson, S. Stones-Havas, M. Cheung, S. Sturrock, S. Buxton, A. Cooper, S. Markowitz, C. Duran, T. Thierer, et al. (2012). Geneious Basic: An integrated and extendable desktop software platform for the organization and analysis of sequence data. Bioinformatics 28:1647-1649.

Kempenaers, B., B. Congdon, P. T. Boag, and R. J. Robertson (1999). Extrapair paternity and egg hatchability in Tree Swallows: Evidence for the genetic compatibility hypothesis? Behavioral Ecology 10:304-311.

Kempenaers, B., S. Everding, C. Bishop, P. T. Boag, and R. J. Robertson (2001). Extra-pair paternity and the reproductive role of male floaters in the Tree Swallow (Tachycineta bicolor). Behavioral Ecology and Sociobiology 49:251-259.

Kimura, M., R. C. Stone, S. C. Hunt, J. Skurnick, X. Lu, X. Cao, C. B. Harley, and A. Aviv (2010). Measurement of telomere length by the Southern blot analysis of terminal restriction fragment lengths. Nature Protocols 5:1596-1607.

Kirkpatrick, M., and N. H. Barton (1997). The strength of indirect selection on female mating preferences. Proceedings of the National Academy of Sciences USA 94:1282-1286.

Lack, D. (1968). Ecological Adaptations for Breeding in Birds. Chapman and Hall, London, UK.

Le Vaillant, M., V. A. Viblanc, C. Saraux, C. L. Bohec, Y. L. Maho, A. Kato, F. Criscuolo, and Y. Ropert-Coudert (2015). Telomere length reflects individual quality in free-living adult King Penguins. Polar Biology 38:2059-2067.

Levy, M. Z., R. C. Allsopp, A. B. Futcher, C. W. Greider, and C. B. Harley (1992). Telomere end-replication problem and cell aging. Journal of Molecular Biology 225:951-960.

Lifjeld, J. T., and R. J. Robertson (1992). Female control of extrapair fertilization in Tree Swallows. Behavioral Ecology and Sociobiology 31:89-96.

Lombardo, M. P. (1986). Extrapair copulations in the Tree Swallow. The Wilson Bulletin 98:150-152.

Lombardo, M. P., A. N. Forman, M. R. Czarnowski, and P. A. Thorpe (2002). Individual, temporal, and seasonal variation in sperm concentration in Tree Swallows. The Condor 104:803810.

Lombardo, M. P., M. L. Green, P. A. Thorpe, M. R. Czarnowski, and H. W. Power (2004). Repeated sampling affects Tree Swallow semen characteristics. Journal of Field Ornithology 75:394403.

Magrath, M. J. L., O. Vedder, M. van der Velde, and J. Komdeur (2009). Maternal effects contribute to the superior performance of extra-pair offspring. Current Biology 19:792-797.

Makarewich, C. A., L. M. Stenzler, V. Ferretti, D. W. Winkler, and I. J. Lovette (2009). Isolation and characterization of microsatellite markers from three species of swallows in the genus Tachycineta: T. albilinea, T. bicolor and T. leucorrhoa. Molecular Ecology Resources 9:631-635.

Møller, A. P. (1988). Paternity and paternal care in the swallow, Hirundo rustica. Animal Behaviour 36:996-1005.

Møller, A. P., and R. V. Alatalo (1999). Good-genes effects in sexual selection. Proceedings of the Royal Society of London, Series B 266:85-91.

Monaghan, P., and M. F. Haussmann (2006). Do telomere dynamics link lifestyle and lifespan? Trends in Ecology \& Evolution 21:47-53.

Nussey, D. H., D. Baird, E. Barrett, W. Boner, J. Fairlie, N. Gemmell, N. Hartmann, T. Horn, M. Haussmann, M. Olsson, C. Turbill, et al. (2014). Measuring telomere length and telomere dynamics in evolutionary biology and ecology. Methods in Ecology and Evolution 5:299-310.

R Core Team (2015). R: A language and environment for statistical computing. R Foundation for Statistical Computing, Vienna, Austria.

Saretzki, G., and T. Von Zglinicki (2002). Replicative aging, telomeres, and oxidative stress. Annals of the New York Academy of Sciences 959:24-29.

Schindelin, J., I. Arganda-Carreras, E. Frise, V. Kaynig, M. Longair, T. Pietzsch, S. Preibisch, C. Rueden, S. Saalfeld, B. Schmid, J.-Y. Tinevez, et al. (2012). Fiji: An open-source platform for biological-image analysis. Nature Methods 9:676-682.

Schmoll, T. (2011). A review and perspective on contextdependent genetic effects of extra-pair mating in birds. Journal of Ornithology 152:265-277.

Schmoll, T., A. Quellmalz, V. Dietrich, W. Winkel, J. T. Epplen, and T. Lubjuhn (2005). Genetic similarity between pair mates is not related to extrapair paternity in the socially monogamous Coal Tit. Animal Behaviour 69:1013-1022.

Sheldon, B. C. (1994). Male phenotype, fertility, and the pursuit of extra-pair copulations by female birds. Proceedings of the Royal Society of London, Series B 257:25-30.

Stapleton, M. K., O. Kleven, J. T. Lifjeld, and R. J. Robertson (2007). Female Tree Swallows (Tachycineta bicolor) increase offspring 
heterozygosity through extrapair mating. Behavioral Ecology and Sociobiology 61:1725-1733.

Stenzler, L. (2001). Genetic population structure in two bird species with contrasting dispersal behavior: The Tree Swallow (Tachycineta bicolor) and the Florida Scrub-jay (Aphelocoma coerulescens). M.Sc. thesis, Cornell University, Ithaca, NY, USA.

Townsend, A. K., A. B. Clark, and K. J. McGowan (2010). Direct benefits and genetic costs of extrapair paternity for female American Crows (Corvus brachyrhynchos). The American Naturalist 175:E1-E9.

Tregenza, T., and N. Wedell (2000). Genetic compatibility, mate choice and patterns of parentage: Invited review. Molecular Ecology 9:1013-1027.

Venier, L. A., P. O. Dunn, J. T. Lifjeld, and R. J. Robertson (1993). Behavioural patterns of extra-pair copulation in Tree Swallows. Animal Behaviour 45:412-415.

Watson, H., M. Bolton, and P. Monaghan (2015). Variation in early-life telomere dynamics in a long-lived bird: Links to environmental conditions and survival. Journal of Experimental Biology 218:668-674.

Westneat, D. F., P. W. Sherman, and M. L. Morton (1990). The ecology and evolution of extra-pair copulations in birds. In Current Ornithology, Volume 7 (D. M. Power, Editor). pp. 331369.
Wetton, J. H., and D. T. Parkin (1991). An association between fertility and cuckoldry in the House Sparrow, Passer domesticus. Proceedings of the Royal Society of London, Series B 245:227-233.

Whittingham, L. A., and P. O. Dunn (2000). Offspring sex ratios in Tree Swallows: Females in better condition produce more sons. Molecular Ecology 9:1123-1129.

Whittingham, L. A., and P. O. Dunn (2001). Survival of extrapair and within-pair young in Tree Swallows. Behavioral Ecology 12:496-500.

Whittingham, L. A., and P. O. Dunn (2010). Fitness benefits of polyandry for experienced females. Molecular Ecology 19: 2328-2335.

Whittingham, L. A., and P. O. Dunn (2014). Extra-pair mating and sexual selection on male traits across populations. The Wilson Journal of Ornithology 126:9-18.

Whittingham, L. A., and P. O. Dunn (2016). Experimental evidence that brighter males sire more extra-pair young in Tree Swallows. Molecular Ecology 25:3706-3715.

Whittingham, L. A., P. O. Dunn, and M. K. Stapleton (2006). Repeatability of extra-pair mating in Tree Swallows. Molecular Ecology 15:841-849.

Williams, G. C. (1975). Sex and Evolution. Princeton University Press, Princeton, NJ, USA.

Wolf, L. L. (1975). "Prostitution" behavior in a tropical hummingbird. The Condor 77:140-144. 